\title{
Vitrification of blastocysts at various degrees of blastocoele expansion using different exposure times to the equilibration solution ${ }^{\mathrm{a}}$
}

\author{
Tamara Lamin ${ }^{1 *}$, Rodrigo Sant'Ana², Alfred Paul Senn³, Rafael Alonso Salvador ${ }^{1}$, David Til', Larissa Benvenutti', \\ Vera Lucia Langaro Amaral' \\ 'Universidade do Vale do Itajaí (UNIVALI), Laboratório de Biotecnologia da Reprodução, Itajaí, SC, Brasil \\ Universidade do Vale do Itajaí (UNIVALI), Laboratório de Oceanografia Biológica, Itajaí, SC, Brasil \\ ${ }^{3}$ FertasBrasil, Balneário Camboriú, SC, Brasil
}

\begin{abstract}
Objectives: To evaluate the efficiency of a vitrification protocol of murine blastocysts, varying the exposure time to the equilibrium solution, at different degrees of blastocoel expansion. Methods: Sixty female mice were superovulated with 10 IU of equine chorionic gonadotropin (eCG, Novormon ${ }^{\circledR}$, Syntex, Argentina) and after 48 hours with $10 \mathrm{IU}$ of human chorionic gonadotropin (hCG, Vetecor ${ }^{\circledR}$, Calier, Barcelona, Spain). Females were then coupled with males overnight, and the presence of vaginal plug indicated that mating had occurred. Three days later, females were euthanized and the embryos at the morula stage $(n=925)$ were recovered by flushing the uterine tubes with GV-Hepes medium (Ingámed ${ }^{\circledast}$, Maringá, Brazil). Embryos were then cultivated until the blastocyst stage and classified, at the time the vitrification process was initiated, into 3 groups $(G 1, G 2, G 4)$ according to the degree of blastocoele expansion. A control group remained in culture until hatching. All embryos, after warming, were put back into culture for measurement of the rehydration (RR) and hatching (HR) rates. Results: For G1 group, the mean RR and HR obtained over a range of exposure times to the equilibration solution of 94.0 and $84.4 \%$, respectively. For G2, these rates were 95.2 and $87.1 \%$, respectively. For G1 and G2, RR and HR obtained after an equilibration time of 9 min were statistically higher than those obtained after 10, 11, 12, 13 and 14 min. For G4, RR and HR were 76.4 and $69.9 \%$, respectively, but in this case, an equilibration time of 15 min presented statistically higher survival rates compared to shorter exposition times. Conclusions: The results of this study indicate that the variation in the exposure time of the embryos to the equilibration solution influences significantly the rehydration and hatching of the blastocysts, and the degree of blastocoel expansion is inversely correlated with the survival and development potential after warming.
\end{abstract}

Keywords: vitrification; blastocysts; blastocoel; cryoprotectant.

\section{Introduction}

Cryopreservation is a technique widely used in assisted reproduction to preserve the viability of gametes, embryos and germinative tissue ${ }^{1}$. Vitrification is the most recent method of cryopreservation and consists of an ultra-rapid freezing using high cryoprotectants concentrations ${ }^{2}$. Many variables are involved in this process such as the type, concentration, and volume of the cryoprotectants, the time of exposure and the temperature during the equilibration period, the type of supporting device, and the cooling rate. Such variables need individual adjustments according to the biological sample and many laboratories need to develop or adapt their own freezing protocols².

Ice crystals formation are the main cause of cell membrane and organelle damage during the freezing procedure, but the high concentration of cryoprotectants can also induce cell damage due to osmotic stress and chemical toxicity ${ }^{3}$. Cryoprotectant solutions contain mixtures of permeable or non-permeant agents, macromolecules and carbohydrates, aiming the prevention of cell membrane lesions during cooling and warming steps. For successful vitrification, the

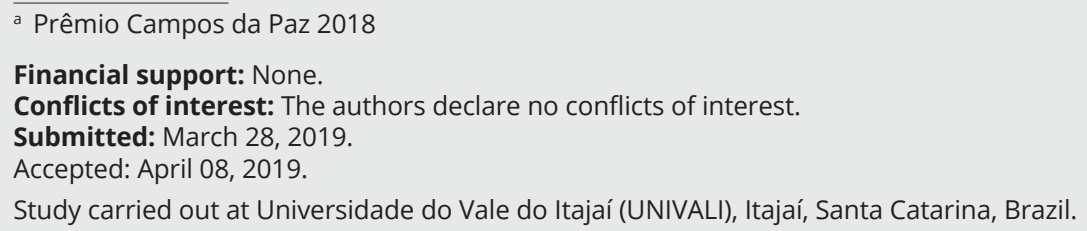

Copyright Lamin et al. This is an Open Access article distributed under the terms of the Creative Commons Attribution License, which permits unrestricted use, distribution, and reproduction in any medium, provided the original work is properly cited. 
achievement of a high cooling rate is essential to reach cellular survival and this can be obtained through direct contact between cells and liquid nitrogen 4 .

The cryoprotectants differ through their intracellular or extracellular mode of action. Intracellular cryoprotectants are hydrophilic molecules of low molecular weight that have the capacity to permeate the cell membrane and to bind to water molecules through hydrogen bonds, conferring a vitreous state that makes the whole cellular structure more flexible and less susceptible to ice crystals formation ${ }^{5}$. The most utilized molecules are ethylene glycol (EG), propylene glycol (PROH), dymethyl sulfoxide (DMSO) and glycerol' ${ }^{1}$. Extracellular cryoprotectants do not permeate cell membranes and are responsible for osmotic cell dehydration which avoids intracellular ice crystal formation during freezing. They also reduce the intracellular cryoprotectant concentration, decreasing the solution toxicity ${ }^{6}$. The most used molecules include sugars like glucose, sucrose and trehalose, alongside albumin, polyviniypyrrolidone (PVP) and egg yolk.

The choice of a cryoprotectant must take into consideration its molecular weight, toxicity level, permeability capacity and the type of biological material to be cryopreserved. Exposure time to cryoprotectants must be limited, due to their toxicity, however short exposure times may lead to an incomplete permeation, that might lead to ice crystal formation during freezing ${ }^{7}$. Although high concentrations of cryoprotectants may be toxic, adjustments of the vitrification protocol may reduce the aforementioned lethal effect while minimizing ice crystal formation ${ }^{4}$. According to Liebermann et al. ${ }^{8}$, osmotic and toxic effects can be minimized using a combination of two cryoprotectants and exposing the sample to a stepwise increase of the concentration of the equilibration solution. Another strategy is to adequate the exposure time to the equilibration solution for each sample to be cryopreserved ${ }^{9}$.

During embryo development, from zygote to blastocysts, embryonic cells are subjected to a series of morphological and metabolic modifications, which result in distinct sensitivities to the cryopreservation process ${ }^{10}$. For instance, at the morula stage, the blastocyst formation starts with the development of the blastocoel, the inner cell mass and the trophectoderm ${ }^{11}$. The degree of blastocoel expansion during blastocyst enlargement may influence the time needed for the embryo to establish an osmotic equilibrium. Despite the use of cryoprotectants at high concentrations and the osmotic shrinkage of the blastocoel volume, expanded blastocysts are still prone to ice crystal formation due the remainder of a variable amount of water-based fluids in the blastocyst cavity ${ }^{4,8,12}$. A decrease in the survival rate of blastocysts after vitrification was observed when the volume of the blastocyst cavity was important ${ }^{13}$. Such changes were also observed in previous studies using morulae, early blastocysts, blastocysts and expanded blastocysts. In order to improve such results, efforts were made regarding in vitro culture conditions and the selection of specific cryopreservation protocols for each development stage, particularly, for expanded blastocysts ${ }^{4,13}$.

The aim of this study was to evaluate the efficiency of a blastocyst vitrification protocol altering time exposure of the blastocysts to the equilibration solution using embryos at different stages of blastocoel expansion.

\section{Methods}

The protocol of this study was approved by the Ethics Committee of Animal Use (CEUA) of the Vale do Itajai University (UNIVALI) under the registered number 017/16.

Sixty F1 (Balb/c X C57BL/6) female mice (Mus musculus), were used as embryo donors. Six F1 (Balb/c X C57BL/6) adult males were used for in vivo fertilization and 26 female mice (SWISS) 8 to 10 weeks old, were used as embryo receptors. All animals were obtained from the Central Animal Facility of UNIVALI. The animals were kept for acclimatization in the Laboratory of Reproductive Biotechnology (LBR) during one week before starting the experiments. They were held in cages with water and food ad libitum and PVC tubes as environmental enrichment. The animal facility was maintained at a controlled temperature of $22 \pm 2^{\circ} \mathrm{C}$, with a light/dark cycle of $12 / 12$ hours.

For ovarian induction, female donors were stimulated with 10UI eCG (Novormon ${ }^{\circledR}$, Syntex, Argentina) and, after 48 hours with 10UI hCG (Vetecor ${ }^{\circledR}$, Calier, Spain). Females were then paired with males for mating and left together overnight. In the followed morning, copulation was confirmed by the presence of a vaginal plug ${ }^{14}$. Three days after mating, females were euthanized in a $\mathrm{CO}_{2} / \mathrm{O}_{2}$ chamber. Embryos were recovered at the morula stage $(\mathrm{N}=925)$ by flushing the uterine tubes with GV-Hepes (Ingámed ${ }^{\circledR}$, Maringá, Brazil). Embryos were grown in polystyrene plates (15x60mm, Ingámed ${ }^{\circledR}$, Maringá, Brazil), in 20 $\mu \mathrm{L}$ droplets of GV-Blast medium (Ingámed ${ }^{\circledR}$, Maringá, Brazil) supplemented with 10\% of synthetic serum (Ingámed ${ }^{\circledR}$, Maringá, Brazil). Culture plates were kept $(72 \mathrm{~h})$ under $5 \% \mathrm{CO}_{2}$ at $37^{\circ} \mathrm{C}$ until the embryos reached the blastocyst stage.

Blastocysts ( $N=813$ ) were then separated according to their degree of blastocoel ${ }^{15}$ into three groups (G1, G2 and G4). Stage 1 (G1) corresponds to early blastocysts in which the blastocoel occupies less than $50 \%$ of the embryo volume. In stage 2 (G2), the blastocoel occupies half or more of the blastocyst total volume. In stage 3, the blastocoel occupies the whole embryo (full blastocyst). In stage 4 (G4), the volume of the blastocyst has increased and the zona pellucida has become thinner. In stage 5, the trophectoderm begins to herniate through the zona pellucida. Finally, in stage 6 , the blastocyst has hatched out of the zona pellucida. 
Classified blastocysts were then exposed to the equilibration solution for increasing times (9-15 min, Figure 1) and mounted on vitrification straws (Ingámed ${ }^{\circledR}$, Maringá, Brazil) in groups of 5/straw, before storage in liquid nitrogen. Embryo warming was performed using the warming solution Ingámed ${ }^{\circledR}$ (Maringá, Brazil) according to the protocol below. After the warming procedure, embryos were put back in order to determine the re-expansion and hatching rates.

\section{Vitrification}

For the equilibration phase, embryos were deposited in $20 \mu \mathrm{L} \mathrm{GV}$-Hepes medium. Using the tip of a sterile pipette, a junction was then established with the first equilibration solution drop VI-1 and embryos were kept in this mixture for $3 \mathrm{~min}$. Afterward, the second drop of $\mathrm{VI}-1(20 \mu \mathrm{L})$ was mixed to the Hepes + VI-1 solution for another 3 min. Embryos were then transferred to a third VI-1 $(20 \mu \mathrm{L})$ drop, in which they remained for different times of 9, 10, 11 and 12 min. By the end of this equilibration phase, cryoprotectants were assumed to have filled the blastocoel as the initial volume was recovered. Embryos were then washed in three drops $(20 \mu \mathrm{L})$ of $\mathrm{VI}-2$, keeping the transfer of medium to a minimum and were deposited by groups of 5 on a vitrification straw before immersion in $\mathrm{LN}_{2}$. Total time in this stage didn't exceed 1 minute.

\section{Warming}

For warming, straws were retrieved from the $\mathrm{LN}_{2}$ tank and immediately immersed in a $150 \mu \mathrm{L}$ drop of a warming solution DV-I (Ingámed ${ }^{\circledR}$, Maringá, Brazil) pre-heated at $37^{\circ} \mathrm{C}$. After 1 min, embryos were transferred to a $100 \mu \mathrm{L}$ drop of a DV-II washing solution for 3 min. Finally, the embryos were rinsed in two subsequent drops of DV-III washing solution for $5 \mathrm{~min}$ in each drop to fully remove the remaining cryoprotectants. Embryos were put back in culture to evaluate blastocoel re-expansion rates (after $4 \mathrm{~h}$ ) and hatching rates (after $24 \mathrm{~h}$ ).

\section{Vasectomy}

For vasectomy, males were anesthetized with a mixture of acepromazine $1 \%$ ( $3 \mathrm{mg} / \mathrm{kg}$ ), ketamine chloride (100 mg/kg) and xylazine chloride $2 \%(20 \mathrm{mg} / \mathrm{kg})$ according to the standard procedure of the laboratory ${ }^{16}$. A transversal incision of $1.5 \mathrm{~cm}$ was performed in the abdomen to access the corporal cavity and for epididymal fat exposure. The vas deferens was localized sectioned and cauterized. After placing back the epididymal fat and other structures in the abdominal cavity, the incision was sutured and the animals were kept in observation at $37^{\circ} \mathrm{C}$ for $24 \mathrm{~h}$. At the end of the procedure, Ketofen ( $5 \mathrm{mg} / \mathrm{kg}$ ) was administered as analgesic. Signals of discomfort such as piloerection, habits changes and prostrated posture were noted alongside with the return of normal physiological excretion functions ${ }^{17}$. The vasectomized males were only used after a recuperation period of 2 weeks.

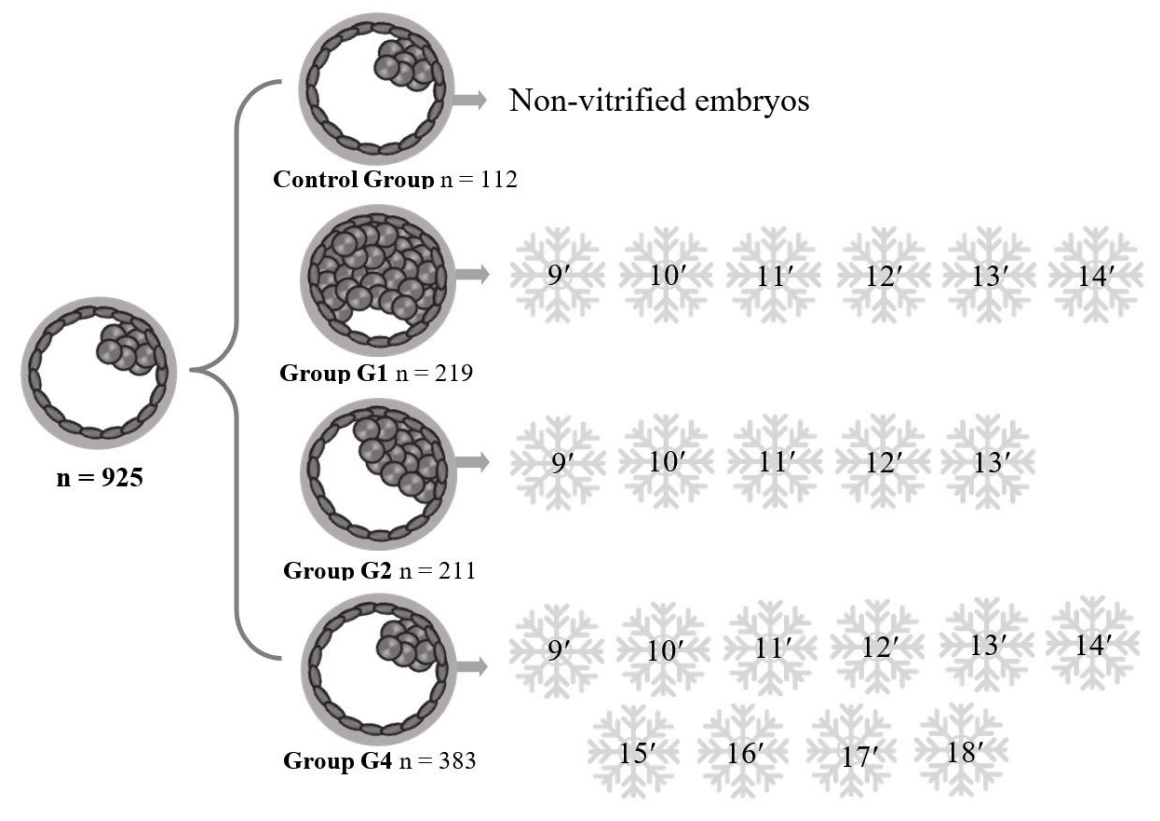

Figure 1. Detail of the experimental groups, demonstrating the number of embryos vitrified by Group in each time (min) of exposure to the equilibrium solution. 


\section{Embryo transfer}

Recipient females (SWISS) were paired in individual boxes with vasectomized males for an overnight cohabitation. Copulation was identified by the presence of a vaginal plug on the following morning. After 2-4 days pseudopregnancy, female recipients were anesthetized with a mixture of acepromazine $1 \%$ (3 mg/kg), ketamine chloride $(100 \mathrm{mg} / \mathrm{kg})$ and xylazine chloride $2 \%(20 \mathrm{mg} / \mathrm{kg})^{16}$. Once anesthetized, females were deposited under a stereomicroscope in a ventral decubitus position. Following localized iodine disinfection, a longitudinal incision of $1 \mathrm{~cm}$ was performed in the female's dorsum and peritoneum in order to expose the uterine horn and Fallopian tubes. For each group of treatment (G1, G2, and G4), about 10 embryos of warmed blastocysts were aspirated into a stretched glass capillary and transferred into a uterine horn through the perforation created shortly before by a $0.45 \times 13 \mathrm{~mm}$ needle.

At the end of the procedure, the incisions were sutured and the animals were kept in observation at $37^{\circ} \mathrm{C}$ for $24 \mathrm{~h}$ and after administration of Ketofen $(5 \mathrm{mg} / \mathrm{kg}$ ) as an analgesic. Signals of discomfort such as piloerection, habits changes, and prostrated posture were noted alongside with the return of physiological excretion functions ${ }^{17}$.

\section{Implantation and pregnancy rates}

Sixteen days after embryo transfer, implantation and pregnancy rates were evaluated by counting the implantation points. Recipient females were euthanized in a gazed chamber containing a $\mathrm{CO}_{2} / \mathrm{O}_{2}$ mixture of $30 \% / 70$. Uterine horns were exposed, removed and immediately immersed in $\mathrm{LN}_{2}$. After this procedure, the uterine horns were dissected and the numbers of fetus and implantation points were counted under a stereomicroscope.

\section{Data and statistical analysis}

Generalized linear models (GLMs) were applied according to Nelder and Wedderbur ${ }^{18}$ to investigate possible success rate in each stage previously described (re-expansion and hatching) and for the different equilibration times evaluated in this study.

In summary, GLMs are characterized by greater flexibility in the analytical proposition, since they allow a relaxation on the assumption that the random variable response to be analyzed must follow a normal distribution. In general, GLMs denote the relation between the variable response yi $(i=1, \ldots, n)$ through predictors $x i$. It is assumed that conditional distribution of yi | xi belongs to the exponential family, with function given by Equation 1:

$$
f(y ; \theta, \phi)=\exp \{(y \theta-b(\theta)) / a(\phi)+c(y, \phi)\}
$$

For known functions $\mathrm{a}(),. \mathrm{b}($.$) and \mathrm{c}($.). The $\phi$ dispersion parameter is generally known, thus, $\theta$ is the canonic parameter of the previously presented function ${ }^{19}$. With this condition satisfied, the average is conditioned to yi to the predictors or explanatory variables $\mathrm{xi}$ is determined as $\mathrm{E}(\mathrm{yi} \mid \mathrm{xi})=\mu \mathrm{i}$ and $\mu \mathrm{i}$ can be transformed as follows in Equation 2 :

$$
g\left(\mu_{i}\right)=x_{i}^{T} \beta
$$

where $g($.$) is a known binding function and \beta$ is the parameter vector to be estimated. The variance of yi is given by $\operatorname{Var}(\mathrm{yi})=\varphi \mathrm{V}\left(\mu_{-} \mathrm{i}\right)$, where $\varphi$ is the dispersion parameter (usually constant) and $\mathrm{V}\left(\mu_{-} \mathrm{i}\right)$ is the variance function ${ }^{19}$. In this specific case, since the response variables are success / failure proportions, binomial models were designed for each degree of blastocoel expansion, assuming a level of significance of 0.05 . These models had as general notation the logistic regression model described below (Equation 3). Statistical analyzes of the present study were performed using software R 3.5.0 (R Core Team).

$$
\log \left(\frac{\pi(x)}{1-\pi(x)}\right)=\beta_{0}+\beta_{1} x_{1}+\beta_{2} x_{2}+\ldots+\beta_{p} x_{p}
$$

\section{Results}

The number of vitrified embryos, as well as the re-expansion and hatching rates found in group G1 for the different exposure times to the equilibration solution, are presented in Table 1. This group had an average re-expansion rate of $94.0 \%$ and an average hatching rate of $82.3 \%$. The analysis of the deviation model in the re-expanded/vitrified ratio shows that the variation in the exposure times to the equilibration solution tends to reduce significantly $(p=0.0003)$ the variability in the re-expansion rates (Table 2). The times with the highest rates were 9, 11 and 12 min (100\%), 
followed by 10 and 13 min (97.4 and 92.9\%, respectively). The time of 14 min presented the lowest re-expansion rate when compared to the others. However, there was no statistically significant difference between the times for this group (Table 1). In relation to the hatched/vitrified ratio of the same group, the variation in embryo exposure times to the equilibrium solution was also significant $(p=0.02)$ (Table 3). It was observed that the time of 9 min, although not having the highest rate, was statistically significant $(p=0.00001)$. The times of 13 and 14 min were worse, due to the low rates. The other times did not present significant differences between them.

In group G2, the number of vitrified embryos as well as the rates of re-expansion and hatching for the different exposure times to the equilibration solution are shown in Table 4. The group had a mean re-expansion rate of $95.2 \%$ and a hatching average of $83 \%$. The deviation model analysis of the re-expanded/vitrified ratio, demonstrates that the time of exposure to the equilibration solution influences the embryo re-expansion during the vitrification process $(p=0.01)$ (Table 5). The times that presented the highest rates were 9 and $12 \min (100 \%)$, followed by 10 and 11 minutes ( 95.9 and $95.6 \%$, respectively). The time of 13 min presented the lowest re-expansion rate in comparison to the others. However, there was no statistically significant difference between the times (Table 4, 5 and 6).

The group G4 presented a 76.4\% re-expansion and a 53.7\% hatching rate. The number of vitrified embryos, re-expansion and hatching rates are presented in Table 7. Based on the deviation model analysis in the re-expanded/vitrified ratio, a significant ( $p=0.0001$ ) influence of the time variation can be observed for re-expansion (Table 8). The time of 15 min showed greater statistical significance $(p=0.005)$ when compared to the others. In the hatched/vitrified ratio of the same group, using the deviation model analysis, it was also observed that the time variation was in this case significant $(p=0.01$ ) for embryo hatching (Table 9). The best time found was $15 \mathrm{~min}$, which was statistically different from the others

Table 1. Number of re-expanded and hatched embryos ( \pm standard error) and group G1 re-expansion and hatching rates at different exposure times to the equilibrium solution

\begin{tabular}{|c|c|c|c|c|c|c|}
\hline \multicolumn{7}{|c|}{ Group G1 } \\
\hline \multirow{2}{*}{ Time(min) } & \multicolumn{2}{|c|}{ Re-expansion } & \multicolumn{2}{|c|}{ Hatching/Re-expansion } & \multicolumn{2}{|c|}{ Hatching/Vitrified } \\
\hline & $\mathbf{n}$ & $(\%)$ & $\mathbf{n}$ & $(\%)$ & $\mathbf{n}$ & $(\%)$ \\
\hline Control & $110 / 112$ & - & $106 / 110$ & 96.4 & $106 / 112$ & 94.6 \\
\hline 9 & $43 / 43( \pm 7101.0)$ & 100.0 & $39 / 43$ & 90.7 & $39 / 43( \pm 0.52)$ & $90.7 * * *$ \\
\hline 10 & $37 / 38( \pm 7101.0)$ & 97.4 & $36 / 37$ & 97.3 & $36 / 38( \pm 0.90)$ & 94.7 \\
\hline 11 & $45 / 45( \pm 10230.0)$ & 100.0 & $39 / 45$ & 86.7 & $39 / 45( \pm 0.68)$ & 86.7 \\
\hline 12 & $46 / 46( \pm 10010.0)$ & 100.0 & $40 / 46$ & 87.0 & $40 / 46( \pm 0.68)$ & 87.0 \\
\hline 13 & $26 / 28( \pm 7101.0)$ & 92.9 & $20 / 26$ & 77.0 & $20 / 28( \pm 0.67)$ & $71.4^{*}$ \\
\hline 14 & $14 / 19( \pm 7101.0)$ & 73.7 & $12 / 14$ & 85.7 & $12 / 19( \pm 0.71)$ & $63.2^{*}$ \\
\hline
\end{tabular}

Table 2. Analysis of the deviation model. G1 re-expanded/vitrified rate

$\begin{array}{ccccc}\text { Parameters } & \text { G.L } & \text { Deviance } & \text { Residual G.L. } & \text { Residual deviance } \\ \text { NULL } & & 42 & 35.96 \\ \}^{\wedge \wedge \text { mTime }} & 5 & 23.10 & 37 & 12.86 \\ * * \star p<0.001 . & & & & 0.0003232 * * *\end{array}$

Table 3. Analysis of the deviation model. G1 Hatched/vitrified rate

\begin{tabular}{ccccc} 
Parameters & G.L & Deviance & Residual G.L. & Residual deviance \\
NULL & & 42 & 57.56 \\
Time & 5 & 13.90 & 37 & 43.66 \\
\hline
\end{tabular}

${ }^{*} p<0.05$. 
Table 4. Number of re-expanded and hatched embryos ( \pm standard error) and group $\mathrm{G} 2$ re-expansion and hatching rates at different exposure times to the equilibrium solution

\begin{tabular}{|c|c|c|c|c|c|c|}
\hline \multicolumn{7}{|c|}{ Group G2 } \\
\hline \multirow{2}{*}{ Time(min) } & \multicolumn{2}{|c|}{ Re-expansion } & \multicolumn{2}{|c|}{ Hatching/Re-expansion } & \multicolumn{2}{|c|}{ Hatching/Vitrified } \\
\hline & $\mathbf{n}$ & $(\%)$ & $\mathbf{n}$ & $(\%)$ & $\mathbf{n}$ & $(\%)$ \\
\hline Control & $110 / 112$ & - & $106 / 110$ & 96.4 & $106 / 112$ & 94.6 \\
\hline 9 & $44 / 44( \pm 4484.40)$ & 100.0 & $37 / 44$ & 84.1 & $37 / 44( \pm 0.41)$ & $84.1 * * *$ \\
\hline 10 & $47 / 49( \pm 4484.40)$ & 95.9 & $43 / 47$ & 91.5 & $43 / 49( \pm 0.60)$ & 87.8 \\
\hline 11 & $44 / 46( \pm 4484.40)$ & 95.6 & $41 / 44$ & 93.2 & $41 / 46( \pm 0.63)$ & 89.1 \\
\hline 12 & $46 / 46( \pm 6343.0)$ & 100.0 & $39 / 46$ & 84.8 & $39 / 46( \pm 0.73)$ & 84.8 \\
\hline 13 & $22 / 26( \pm 4484.40)$ & 84.6 & $18 / 22$ & 81.8 & $18 / 26( \pm 0.59)$ & 69.2 \\
\hline
\end{tabular}

Table 5. Analysis of the model deviation. G2 Re-expanded/vitrified rate

$\begin{array}{ccccc}\text { Parameters } & \text { G.L } & \text { Deviance } & \text { Residual G.L. } & \text { Residual deviance } \\ \text { NULL } & & 38 & 30.19 & \text { P-valor } \\ \text { Time } & 4 & 12.56 & 34 & 17.63\end{array}$

${ }^{*} \mathrm{p}<0.05$.

Table 6. Analysis of the deviation model. G2 Hatched/vitrified rate

\begin{tabular}{ccccc} 
Parameters & G.L & Deviance & Residual G.L. & Residual deviance \\
NULL & & 38 & 37.74 & P-valor \\
Time & 4 & 8.03 & 34 & 29.72 \\
\hline
\end{tabular}

Table 7. Number of re-expanded and hatched embryos ( \pm standard error) and group G4 re-expansion and hatching rates at different exposure times to the equilibrium solution

\section{Group G4}

\begin{tabular}{|c|c|c|c|c|c|c|}
\hline \multirow{2}{*}{ Time (min) } & \multicolumn{2}{|c|}{ Re-expansion } & \multicolumn{2}{|c|}{ Hatching/Re-expansion } & \multicolumn{2}{|c|}{ Hatching/Vitrified } \\
\hline & $\mathbf{n}$ & $(\%)$ & $\mathbf{n}$ & $(\%)$ & n & $(\%)$ \\
\hline Control & $110 / 112$ & - & $106 / 110$ & 96.4 & $106 / 112$ & 94.6 \\
\hline 9 & $30 / 45( \pm 0.32)$ & $66.7^{\star}$ & $17 / 30$ & 56.7 & $17 / 45( \pm 0,31)$ & 37.8 \\
\hline 10 & $40 / 56( \pm 0.43)$ & 71.4 & $29 / 40$ & 72.5 & $29 / 56( \pm 0,41)$ & 51.8 \\
\hline 11 & $47 / 56( \pm 0.48)$ & $83.9 *$ & $34 / 47$ & 72.3 & $34 / 56( \pm 0,41)$ & $60.7^{*}$ \\
\hline 12 & $45 / 53( \pm 0.50)$ & $84.9 *$ & $34 / 45$ & 75.6 & $34 / 53( \pm 0,42)$ & $64.2^{*}$ \\
\hline 13 & $22 / 26( \pm 0.63)$ & 84.6 & $15 / 22$ & 68.2 & $15 / 26( \pm 0,50)$ & 57.7 \\
\hline 14 & $31 / 35( \pm 0.62)$ & $88.6^{*}$ & $23 / 31$ & 74.2 & $23 / 35( \pm 0,47)$ & $65.7 *$ \\
\hline 15 & $39 / 42( \pm 0.68)$ & $92.9 * \star$ & 28/39 & 71.8 & $28 / 42( \pm 0,45)$ & $66.7 * *$ \\
\hline 16 & $27 / 43( \pm 0.45)$ & 62.8 & $18 / 27$ & 66.7 & $18 / 43( \pm 0,44)$ & 41.9 \\
\hline 17 & $14 / 27( \pm 0.50)$ & 51.8 & $10 / 14$ & 71.4 & $10 / 27( \pm 0,50)$ & 37.0 \\
\hline
\end{tabular}

${ }^{*} \mathrm{p}<0.05 ;{ }^{* *} \mathrm{p}<0.01$. 
Table 8. Analysis of the model deviation. G4 Re-expanded/vitrified rate

$\begin{array}{ccccc}\text { Parameters } & \text { G.L } & \text { Deviance } & \text { Residual G.L. } & \text { Residual deviance } \\ \text { NULL } & & 64 & 107.48 \\ \text { Time } & 8 & 31.24 & 56 & 76.23 \\ * * * p<0.001 . & & & & 0.000127 * * *\end{array}$

Table 9. Analysis of the deviation model. G4 Hatched/vitrified rate

\begin{tabular}{ccccc} 
Parameters & G.L & Deviance & Residual G.L. & Residual deviance \\
NULL & & 64 & 132.25 \\
Time & 8 & 18.708 & 56 & 113.54 \\
\hline
\end{tabular}

${ }^{*} \mathrm{p}<0.05$

$(p=0.008)$. The times that presented the highest hatching rates were 15,14 and 12 min $(66.7,65.7$ and $64.2 \%)$ followed by 11,13 and $10 \mathrm{~min}(60.7,57.7$ and 51, 8\%).The times of 16,9 and 17 min showed the lowest rates $(41.9,37.8$ and $37.0 \%$, respectively) in comparison to the others (Table 7).

For the transfer experiments, 26 females were used, resulting in two embryo implantation sites of fresh transferred embryos, one implantation site and six births of vitrified embryos, of a total of 10 embryos transferred each.

\section{Discussion}

Post-vitrification blastocyst survival is affected by both the blastocoele expansion and the equilibration time prior to freezing. In the present study, we showed that re-expansion and hatching rates were superior when blastocysts were vitrified at the initial stage of blastocoele expansion (G1) and exposed for the shortest time (9 min) to the equilibration solution. As this time was increased, the post-vitrification re-expansion rate decreased. Similar observations were made when using blastocysts at a later stage of expansion (G2).

For fully expanded blastocysts (G4), the survival and hatching rates increased when the equilibration time was increased up to $15 \mathrm{~min}$, but decreased thereafter. These time-related effects can be explained by the toxic action of the highly concentrated cryoprotectants needed for vitrification, which can lead to embryo death when exposition occurs for a prolonged time ${ }^{20}$. The inverse relationship between blastocoele expansion and efficiency of vitrification, observed in the present study, has also been observed with human embryos ${ }^{21,22}$.

Independently of embryo quality or developmental stage, the vitrification process may cause a reduction in mitochondrial activity and a disorganization of actin filaments, which compromise the succeeding developmental processes of the embryo $^{23}$. A change in the mitochondrial activity affects the rate of oxygen consumption and the re-expansion of the blastocoele cavity after embryo warming 24 . Many cryoprotectants are known to promote the depolymerization of microfilaments and microtubules upon contact with the embryo, which prevents the cytoskeleton from being destroyed during cryopreservation ${ }^{25}$. But in expanded blastocysts, the likelihood of ice crystals formation is increased by the larger amount of water present in the blastocoele, leading to a lower efficiency of the cryo protectants and increased destruction of essential cells ${ }^{25,26}$.

The time needed for re-expansion of the blastocoele after warming affects the implantation and clinical pregnancy rates: the longer the time needed for re-expansion the lower is the implantation rate $20,27-29$. There is, however, no clear threshold in the re-expansion time above which there are no clinical pregnancies. This might be due to the fact that good quality embryos may recover more easily from the damages caused by the vitrification process and thus retain a good implantation potential ${ }^{30}$.

Contrary to what we saw in this study, several authors found that survival rates, and subsequent implantation and birth rates were higher when the degree of blastocoele expansion was high and when an artificial collapse of the blastocoele cavity was induced before vitrification ${ }^{13,29,31-33}$. Blastocoele collapse can be achieved mechanically by aspiring the blastocoele liquid with a micropipette or by inducing a releasing of this liquid using a laser shot ${ }^{22,34}$. Several studies have shown that high-quality early blastocyst embryos (G1 and G2) do not systematically develop to viable fully expanded blastocyst able to hatch and implant $29,32,35$. 
The advantage of using fully expanded blastocyst is associated with the fact that these embryos may have been selected further through culture and thus have a higher implantation and live birth rates than less expanded ones $(\mathrm{G} 1, \mathrm{G} 2)$. Once the collapse of the blastocoele has taken place in a G4 blastocyst, the cells occupy a smaller volume and are more easily permeated by the cryoprotectants.

In our study, the rates of blastocoele re-expansion were similar in G1 (82.3\%) and G2 (83.0\%) when a pre-equilibration time of 9 min was used. In these groups, the mean hatching rate was $53.7 \%$ a value that is significantly lower than that of the control group (94.6\%). There are various reasons for this decline, a lack of viability, the timing of each step, a hardening of the zona pellucida caused by the freezing procedure ${ }^{36-38}$.

In our study, the time of exposure to the equilibration solution interfered significantly with the rates of blastocyst re-expansion and hatching, but still presented higher rates when compared to other studies.

Vitrification is still a young science and embryologists tend to adapt the manufacturer's instruction to their own needs, both in terms of equilibration time and stage of the embryos at the time of vitrification. The art of vitrification consists of finding the right balance between cryoprotectants concentration and equilibration time, with the aim to maximize dehydration while minimizing toxic effects. Many protocols were published along these lines ${ }^{13,39,40}$, but the idea which seems to emerge is that the higher the cryoprotectant concentration the lower the equilibration time should be. However, the importance of the blastocyst developmental stage cannot be neglected.

The early blastocyst stage, which has a small number of blastomeres and a low volume, is an ideal stage for vitrification due to the shorter equilibration time required ${ }^{40}$. As blastocysts develop, both the blastocoele and the number of cells increase, and so does the need for equilibrium with the cryoprotectants ${ }^{41}$.

Although specific protocols for each embryonic stage can be found, there is still a question about the optimum degree of expansion of the blastocoele, which, once elucidated, could improve embryo survival and implantation rates even further.

The successful in vitro culture of embryos up to the blastocyst stage has increased the need for a suitable protocol for blastocyst cryopreservation and a better understanding of the ideal stage to do so. In mice, we conclude that the equilibration time in the cryoprotectant solution is an essential factor and that this time should be adapted to the size of the blastocoele cavity.

\section{Conclusion}

The results of this study indicate that the variation in the exposure time of the embryos to the equilibrium solution significantly influences the blastocyst re-expansion and hatching, and that the degree of blastocyst expansion is inversely proportional to the survival potential presented after warming.

It can be concluded that the times that presented the best results for re-expansion and hatching, according to the degree of the blastocoel expansion, were 9 minutes (G1 and G2) and 15 minutes (G4). However, further studies are still needed to evaluate the efficiency of these times in implantation and pregnancy rates.

\section{References}

1. Almodin CG, Costa RR. Criopreservação em reprodução. Maringá: DentalPress; 2014. 292 p.

2. Wong KM, Mastenbroek S, Repping S. Cryopreservation of human embryos and its contribution to in vitro fertilization success rates. Fertil Steril. 2014;102(1):19-26. http://dx.doi.org/10.1016/j.fertnstert.2014.05.027. PMid:24890275.

3. Papadopoulos S, Rizos D, Duffy P, Wade M, Quinn K, Boland MP, et al. Embryo survival and recipient pregnancy rates after transfer of fresh or vitrified, in vivo or in vitro produced ovine blastocysts. Anim Reprod Sci. 2002;74(1-2):35-44. http://dx.doi. org/10.1016/S0378-4320(02)00162-8. PMid:12379373.

4. Kader AA, Choi A, Orief Y, Agarwal A. Factors affecting the outcome of human blastocyst vitrification. Reprod Biol Endocrinol. 2009;7(1):99. http://dx.doi.org/10.1186/1477-7827-7-99. PMid:19758458.

5. Carvalho AA, Faustino LR, Figueiredo JR, Rodrigues APR, Costa APR. Vitrificação: uma alternativa para a preservação de embriões e material genético de fêmeas mamíferas em criobancos. Acta Vet Bras. 2012;5(3):236-48.

6. Pereira RM, Marques CC. Animal oocyte and embryo cryopreservation. Cell Tissue Bank. 2008;9(4):267-77. http://dx.doi.org/10.1007/ s10561-008-9075-2. PMid:18496769.

7. Kasai M, Mukaida T. Cryopreservation of animal and human embryos by vitrification. Reprod Biomed Online. 2004;9(2):164-70. http://dx.doi.org/10.1016/S1472-6483(10)62125-6. PMid:15333245.

8. Liebermann J, Nawroth F, Isachenko V, Isachenko E, Rahimi G, Tucker MJ. Potential importance of vitrification in reproductive medicine. Biol Reprod. 2002;67(6):1671-80. http://dx.doi.org/10.1095/biolreprod.102.006833. PMid:12444040.

9. Costa EP, Guimarães JD, Torres CAA, Fagundes LM, Gioso MM. Criopreservação de ovócitos de bovinos imaturos desnudados ou não, utilizando o etilenoglicol pelo método da vitrificação. Rev Bras Zootec. 2002;31(3):1122-9. http://dx.doi.org/10.1590/ S1516-35982002000500008. 
10. Vajta G, Nagy ZP. Are programmable freezers still needed in the embryo laboratory? Review on vitrification. Reprod Biomed Online. 2006;12(6):779-96. http://dx.doi.org/10.1016/S1472-6483(10)61091-7. PMid:16792858.

11. Sadler TW, Langman J. Langman's medical embryology. 12th ed. Philadelphia: Wolters Kluwer Health/Lippincott Williams \& Wilkins; 2012. 384 p.

12. Levi-Setti PE, Menduni F, Smeraldi A, Patrizio P, Morenghi E, Albani E. Artificial shrinkage of blastocysts prior to vitrification improves pregnancy outcome: analysis of 1028 consecutive warming cycles. J Assist Reprod Genet. 2016;33(4):461-6. http:// dx.doi.org/10.1007/s10815-016-0655-y. PMid:26781264.

13. Vanderzwalmen P, Bertin G, Debauche C, Standaert V, van Roosendaal E, Vandervorst M, et al. Births after vitrification at morula and blastocyst stages: effect of artificial reduction of the blastocoelic cavity before vitrification. Hum Reprod. 2002;17(3):744-51. http://dx.doi.org/10.1093/humrep/17.3.744. PMid:11870130.

14. Neto JAL, Almodin CG, da Rosa VB, Amaral VLL, Frajblat M, Câmara VCM. Embryo viability after revitrification with Vitri-ingá ${ }^{\circledR}$ method. JBRA Assist Reprod. 2011;15:15-8.

15. Gardner DK, Schoolcraft WB. In vitro culture of human blastocysts. Reprod Certain Fertil Genet. 1999;1999:378-88.

16. Damy SB, Camargo RS, Chammas R, Figueiredo LFP. Fundamental aspects on animal research as applied to experimental surgery. Rev Assoc Med Bras. 2010;56(1):103-11. http://dx.doi.org/10.1590/S0104-42302010000100024. PMid:20339795.

17. Nagy A, editor. Manipulating the mouse embryo: a laboratory manual. 3rd ed. Cold Spring Harbor: Cold Spring Harbor Laboratory Press; 2003. 764 p.

18. Nelder JA, Wedderburn RWM. Generalized linear models. J R Stat Soc Ser Gen. 1972;135(3):370. http://dx.doi.org/10.2307/2344614.

19. McCullagh P, Nelder JA. Generalized linear models. 2nd ed. London: Chapman and Hall; 1989. 513 p. (Monographs on Statistics and Applied Probability). http://dx.doi.org/10.1007/978-1-4899-3242-6.

20. Shu Y, Watt J, Gebhardt J, Dasig J, Appling J, Behr B. The value of fast blastocoele re-expansion in the selection of a viable thawed blastocyst for transfer. Fertil Steril. 2009;91(2):401-6. http://dx.doi.org/10.1016/j.fertnstert.2007.11.083. PMid:18304536.

21. Hashimoto S, Amo A, Hama S, Ito K, Nakaoka Y, Morimoto Y. Growth retardation in human blastocysts increases the incidence of abnormal spindles and decreases implantation potential after vitrification. Hum Reprod. 2013;28(6):1528-35. http://dx.doi. org/10.1093/humrep/det059. PMid:23482339.

22. Mukaida T, Oka C, Goto T, Takahashi K. Artificial shrinkage of blastocoeles using either a micro-needle or a laser pulse prior to the cooling steps of vitrification improves survival rate and pregnancy outcome of vitrified human blastocysts. Hum Reprod. 2006;21(12):3246-52. http://dx.doi.org/10.1093/humrep/del285. PMid:16936299.

23. Dalcin L, Silva RC, Paulini F, Silva BDM, Neves JP, Lucci CM. Cytoskeleton structure, pattern of mitochondrial activity and ultrastructure of frozen or vitrified sheep embryos. Cryobiology. 2013;67(2):137-45. http://dx.doi.org/10.1016/j.cryobiol.2013.05.012 PMid:23770514.

24. Yamanaka M, Hashimoto S, Amo A, Ito-Sasaki T, Abe H, Morimoto Y. Developmental assessment of human vitrified-warmed blastocysts based on oxygen consumption. Hum Reprod. 2011;26(12):3366-71. http://dx.doi.org/10.1093/humrep/der324. PMid:21972254.

25. Dobrinsky JR. Cellular approach to cryopreservation of embryos. Theriogenology. 1996;45(1):17-26. http://dx.doi. org/10.1016/0093-691X(95)00351-8.

26. Hendriks WK, Roelen BA, Colenbrander B, Stout TA. Cellular damage suffered by equine embryos after exposure to cryoprotectants or cryopreservation by slow-freezing or vitrification. Equine Vet J. 2015;47(6):701-7. http://dx.doi.org/10.1111/evj.12341. PMid:25187202.

27. Coello A, Meseguer M, Galán A, Alegre L, Remohí J, Cobo A. Analysis of the morphological dynamics of blastocysts after vitrification/ warming: defining new predictive variables of implantation. Fertil Steril. 2017;108(4):659-66.e4. http://dx.doi.org/10.1016/j. fertnstert.2017.07.1157. PMid:28863936.

28. Lin R, Feng G, Shu J, Zhang B, Zhou H, Gan X, et al. Blastocoele relexpansion time in vitrified-warmed cycles is a strong predictor of clinical pregnancy outcome. J Obstet Gynaecol Res. 2017;43(4):689-95. http://dx.doi.org/10.1111/jog.13257. PMid:28127833.

29. Yin H, Jiang H, He R, Wang C, Zhu J, Li Y. The effects of blastocyst morphological score and blastocoele re-expansion speed after warming on pregnancy outcomes. Clin Exp Reprod Med. 2016;43(1):31-7. http://dx.doi.org/10.5653/cerm.2016.43.1.31. PMid:27104155.

30. Cobo A, de los Santos MJ, Castellò D, Gámiz P, Campos P, Remohí J. Outcomes of vitrified early cleavage-stage and blastocyststage embryos in a cryopreservation program: evaluation of 3,150 warming cycles. Fertil Steril. 2012;98(5):1138-46.e1. http:// dx.doi.org/10.1016/j.fertnstert.2012.07.1107. PMid:22862909.

31. Ahlström A, Westin C, Wikland M, Hardarson T. Prediction of live birth in frozen-thawed single blastocyst transfer cycles by prefreeze and post-thaw morphology. Hum Reprod. 2013;28(5):1199-209. http://dx.doi.org/10.1093/humrep/det054. PMid:23477908.

32. Du Q-Y, Wang E-Y, Huang Y, Guo X-Y, Xiong Y-J, Yu Y-P, et al. Blastocoele expansion degree predicts live birth after single blastocyst transfer for fresh and vitrified/warmed single blastocyst transfer cycles. Fertil Steril. 2016;105(4):910-9.e1. http:// dx.doi.org/10.1016/j.fertnstert.2015.12.014. PMid:26776910.

33. Goto S, Kadowaki T, Tanaka S, Hashimoto H, Kokeguchi S, Shiotani M. Prediction of pregnancy rate by blastocyst morphological score and age, based on 1,488 single frozen-thawed blastocyst transfer cycles. Fertil Steril. 2011;95(3):948-52. http://dx.doi. org/10.1016/j.fertnstert.2010.06.067. PMid:20674914. 
34. Hur YS, Park JH, Ryu EK, Yoon HJ, Yoon SH, Hur CY, et al. Effect of artificial shrinkage on clinical outcome in fresh blastocyst transfer cycles. Clin Exp Reprod Med. 2011;38(2):87-92. http://dx.doi.org/10.5653/cerm.2011.38.2.87. PMid:22384424.

35. Song W, Wang X, Jin H, Yao G, Zhang X, Shi S, et al. Comparison of vitrified outcomes between human early blastocysts and expanded blastocysts. Vitro Cell Dev Biol - Anim. 2016;52(5):522-9. http://dx.doi.org/10.1007/s11626-016-0009-1.

36. Bertolini M, Costa Lange M, Rodrigues JL. In vitro and in vivo survival of mouse morulas and blastocysts following vitrification in 45\% glycerol. Acta Sci Vet. 2005;33(3):245-51. https://doi.org/10.22456/1679-9216.14944.

37. Bogliolo L, Ledda S, Innocenzi P, Ariu F, Bebbere D, Rosati I, et al. Raman microspectroscopy as a non-invasive tool to assess the vitrification-induced changes of ovine oocyte zona pellucida. Cryobiology. 2012;64(3):267-72. http://dx.doi.org/10.1016/j. cryobiol.2012.02.010. PMid:22387147.

38. Elnahas T, Tawab N, Azmy O, Elnoury A, El-Faissal Y, Fouad T, et al. Prospective randomized trial on the use of laser assisted hatching for transfer of frozen/thawed embryos in human Intracytoplasmic Sperm injection. Middle East Fertil Soc J. 22(4), 309-12.

39. Liebermann J, Tucker MJ. Comparison of vitrification and conventional cryopreservation of day 5 and day 6 blastocysts during clinical application. Fertil Steril. 2006;86(1):20-6. http://dx.doi.org/10.1016/j.fertnstert.2006.01.029. PMid:16762345.

40. Raju GAR, Prakash GJ, Krishna KM, Madan K. Vitrification of human early cavitating and deflated expanded blastocysts: clinical outcome of 474 cycles. J Assist Reprod Genet. 2009;26(9-10):523-9. http://dx.doi.org/10.1007/s10815-009-9356-0. PMid:19876729.

41. Kader A, Choi A, Sharma RK, Falcone T, Agarwal A. Effect of varying equilibration time in a two-step vitrification method on the postwarming DNA integrity of mouse blastocysts. Fertil Steril. 2010;93(8):2640-5. http://dx.doi.org/10.1016/j.fertnstert.2009.07.991. PMid:19732878.

\author{
*Correspondence \\ Tamara Lamin \\ Universidade do Vale do Itajaí (UNIVALI), Laboratório de Biotecnologia da Reprodução \\ Rua Uruguai, 458, Centro \\ CEP 88032-005, Itajaí, SC, Brasil. \\ Tel.: +55 (47) 3341-7961 \\ E-mail: tamaralamin@outlook.com
}

\title{
Author information
}

TL - Biologist graduated at the Universidade do Vale do Itajaí (UNIVALI); RS - Professor at Universidade do Vale do Itajaí (UNIVALI). APS - Researcher and independent consultant at FertasBrasil; RAS - Laboratory Technician at Laboratory of Reproductive Biotechnology, Universidade do Vale do Itajaí (UNIVALI); DT - Professor at Universidade do Vale do Itajaí (UNIVALI); LB - Biomedical graduated at the Universidade do Vale do Itajaí (UNIVALI); VLLA - Professora at Universidade do Vale do Itajaí (UNIVALI).

\section{Author contributions}

TL - execution. RS - statistical analysis. APS - construction of text e translation. RAS - technical assistance. DT - construction of text. LB - translate. VLLA - experimental design. All authors have reviewed and critically approved a final version of the article. 